\title{
An Information System for Risk-Vulnerability Assessment to Flood
}

\author{
Subhankar Karmakar ${ }^{1}$, Slobodan P. Simonovic ${ }^{2}$, Angela Peck ${ }^{2}$, Jordan Black ${ }^{2}$ \\ ${ }^{1}$ Centre for Environmental Science and Engineering, Indian Institute of Technology Bombay, Mumbai, India \\ ${ }^{2}$ Department of Civil and Environmental Engineering, The University of Western Ontario, London, Canada \\ E-mail:skarmakar@iitb.ac.in,simonovic@uwo.ca \\ Received May 18, 2010; revised June 20, 2010; accepted June 25, 2010
}

\begin{abstract}
An exhaustive knowledge of flood risk in different spatial locations is essential for developing an effective flood mitigation strategy for a watershed. In the present study, a risk-vulnerability analysis to flood is performed. Four components of vulnerability to flood: 1) physical, 2) economic, 3) infrastructure and 4) social; are evaluated individually using a Geographic Information System (GIS) environment. The proposed methodology estimates the impact on infrastructure vulnerability due to inundation of critical facilities, emergency service stations and bridges. The components of vulnerability are combined to determine an overall vulnerability to flood. The exposures of land use/land cover and soil type (permeability) to flood are also considered to include their effects on severity of flood. The values of probability of occurrence of flood, vulnerability to flood, and exposures of land use and soil type to flood are used to finally compute flood risk at different locations in a watershed. The proposed methodology is implemented for six major damage centers in the Upper Thames River watershed, located in the South-Western Ontario, Canada to assess the flood risk. An information system is developed for systematic presentation of the flood risk, probability of occurrence of flood, vulnerability to flood, and exposures of land use and soil type to flood by postal code regions or Forward Sortation Areas (FSAs). The flood information system is designed to provide support for different users, i.e., general public, decision-makers and water management professionals. An interactive analysis tool is developed within the information system to assist in evaluation of the flood risk in response to a change in land use pattern.
\end{abstract}

Keywords: Flood Management, Flood Risk, Geographic Information System, Risk Management, Vulnerability Analysis, Information System

\section{Introduction}

Records of loss of life and damage caused by floods worldwide show that these have continued to rise steadily during recent years. Understandably, the response has been to call for increased efforts to protect life and property. The sustainable and effective management of floods demands a holistic approach-linking socio-economic development with the protection of natural ecosystems and appropriate management links between land and water uses. It is recognized that a watershed is a dynamic system in which there are many interactions between human population, land use and water bodies. Assessment and mapping of "flood risk" [1-7] and "vulnerability to flood", and dissemination of the appropriate information to different stakeholders is a very important part of the flo- od management process. The general public may use the information in purchasing a house, or in selecting a site to start a business. Knowledge of flood risk could aid decision-makers in: developing land development plans and land use zoning; planning emergency response strategies; waste disposal site selections; preparing infrastructure budgetary decisions; developing guidelines for operation of existing infrastructure; and general policy development at all levels. Water management professionals can utilize the flood risk information in planning, design, construction, and operation \& maintenance of flood protection infrastructure (e.g., reservoirs, dikes, drainage pipes, etc). Flood risk mapping has been performed extensively for effective flood management, starting with the pioneering work of Garrett [8]. The risk of flooding to towns and villages along $200 \mathrm{~km}$ of the River Thames 
and its tributaries are assessed using a mathematical model developed for Thames Water Rivers Division, UK. The River Thames Strategic Flood Defence Initiative examines the vulnerability of floodplain development along the river. The achievements of the Flood Risk Mapping Program, New Brunswick, Canada, are summarized by Burrell and Keefe [9]. The procedures used to produce flood risk maps are outlined very clearly along with an assessment of the accuracy achieved. Floyd [1] performs a flood risk assessment on the city of Bombay (Mumbai), India. The results provide an initial indication of the cost-effectiveness of different remedial measures. Morris and Flavin [10] present maps of England and Wales showing the built-up areas that would be at flood risk. Shrubsole [11] mentions government responsibilities in flood management of the Saguenay and Red River valley and provides alternative flood management strategies considering ecosystem management, partnerships and the role of science. Hall et al. [12] represents the processes of fluvial and coastal flooding over linear flood defence systems in sufficient detail to test alternative policy options for investment in flood management. Potential economic and social impacts of flooding are assessed using national databases of floodplain properties and demography. A case study of the river Parrett catchment and adjoining sea defences in Bridgwater Bay in England demonstrates the application of the method and presentation of results using Geographic Information System (GIS). Barredo et al. [13] aims to illustrate a framework for flood risk mapping at pan-European scale produced by the Weather-Driven Natural Hazards (WDNH). The threatening natural event is represented as the hazard component, and furthermore, exposure and vulnerability are considered as anthropogenic factors that contribute also to flood risk. The flood risk is considered on the light of exposure, vulnerability and hazard, and mathematically considered as product of hazard, exposure and vulnerability.

Vulnerability assessments have been undertaken to understand the "potential for loss", traditionally they focused on the nature of the hazard and who and what are exposed [14]. More recently, vulnerability assessments have explored the social, economic, and political conditions that are likely to affect the capacity of individuals or communities to cope with or adapt to hazards [15]. Bender [16] discusses the development and use of natural hazard vulnerability assessment techniques in the Americas. He emphasizes how and why a thorough vulnerability analysis is required for physical, economic and social planning in a watershed. There are numerous studies that have addressed contemporary vulnerability of different communities worldwide to flooding from the natural hazards perspective of understanding exposure and the number of people and structures affected $[17,18]$ but few that explore the socio-economic aspects of flo- oding vulnerability [19-22]. Recently, the conceptualization on social vulnerability has gained prominence in the literature. It is related to characteristics that influence an individual's or group's ability or inability to anticipate, cope with, resist, and recover from or adapt to any external stress such as the impact of flooding [23-25]. Cutter et al. [26] present a method for assessing vulnerability in spatial terms using both biophysical and social indicators. Their results suggest that the most biophysically vulnerable places do not always spatially interact with the most vulnerable populations. Flax et al. [27] develop a risk-vulnerability assessment methodology named as Community Vulnerability Assessment Tool (CVAT), which assists emergency managers in their efforts to reduce vulnerabilities through hazard mitigation, comprehensive land use and development planning. Cutter et al. [28] list factors that have gained consensus among social scientists as contributing to social vulnerability to environmental hazards. Blong [29] introduces a new damage index for estimating the replacement cost of damaged buildings in vulnerability analysis. Carter [30] analyzes flood risk as a combination of threat, consequence, and vulnerability. He discusses the federal role in investment decisions for flood control infrastructure. Chakraborty et al. [31] develop two new quantitative indicators, i.e., a geophysical risk index, based on National Hurricane Center and National Flood Insurance Program data, and a social vulnerability index, based on census information. Rygel et al. [32] focus on constructing a social vulnerability index and its application to a case study of hurricane storm hazard. They demonstrate a method of aggregating vulnerability indices for different indicators using Pareto ranking that results in a composite index of vulnerability, which avoids the problems associated with assigning weights. Werritty et al. [33] discuss the social impacts of flood events in Scotland including attitude and behavior toward flooding events, warnings, evacuations and consequences. The study suggests ways for enhancing social resilience for sustainable flood management in Scotland.

GIS is considered as a key tool by many researchers [34-38] to map the spatial distribution of flood risk and vulnerability to flood. A GIS facilitates the input, storage, management, analysis, integration, and output of spatial data which can aid with real time decision making and strategic planning for effective risk management and hazard preparedness [39]. GIS can improve warning, evacuation, and emergency response systems by helping route emergency response vehicles and locating emergency response facilities [39-40]. Exposures of soil and geology to flood, urban infrastructure, and socioeconomic data, can be input and stored in a GIS and then analyzed to identify areas prone to flood, identify vulnerable populations, and forecast flood events, and aid in land use zoning decisions to improve flood mitigation and management [17,39]. 
The flood risk mapping and analysis on various flood prone watersheds have been performed by many researchers throughout the world. In a recent study on Romanian national strategy, Varga et al. [41] provide basic information for preliminary flood risk assessments and flood hazard mapping in all areas with a significant flood risk, according to the Flood Directive. The technical and scientific approach and the main steps in setting up the plan for flood prevention, protection and mitigation at the river basin level are presented. Apel et al. [7] perform flood risk analyses in Eilenburg, Germany, especially in urban areas and tested a number of combinations of models of different complexity both on the hazard (probability of occurrence) and on the vulnerability. Chang et al. [42] examine the anthropogenic and natural causes of flood risks in six representative cities in the Gangwon Province of Korea. Tran et al. [43] explore the impacts of floods on the economy, environment and society; and tries to clarify the rural community's coping mechanism to flood disasters in Central Viet Nam. They reveal that flooding is an essential element for a coastal population, whose livelihood depends on productive functions of cyclical floods. Forster et al. [44] assess flood risk for a rural detention area, alongside the Elbe River in Germany. They find that the losses in agricultural areas exhibit a strong seasonal pattern, and the flooding probability also has a seasonal variation. The flood risk is assessed for a planned detention area based on loss and probability estimation approaches of different time frames, namely a monthly and an annual approach.

The present research study is motivated by the Hotspots project $[45,46]$ completed by the Center for Hazards and Risk Research (CHRR) at Columbia University and the World Bank's Disaster Management Facility [DMF), now the Hazard Management Unit (HMU). In the Hotspots project, the risk levels are estimated by combining hazard or probability of occurrence with historical vulnerability for two indicators of risk-population and Gross Domestic Product (GDP) per unit area-for six major natural hazards: earthquakes, volcanoes, landslides, floods, droughts, and cyclones. The relative risks for each grid cell, rather than country as a whole, is calculated at sub-national scales. Such information can inform a range of disaster prevention and preparedness measures, and development of long-term land-use plans and multihazard risk management strategies. Hotspots global analysis and case studies stimulate additional research, particularly at national and local levels. The present study develops an information system for risk-vulnerability analyses to flood and facilitates vulnerability mitigation by providing various flood information to different users. The information system is designed to provide selective access to information on the bases of user needs. This reduces the misuse of data and promotes data security. A set of suitable vulnerability indicators and the procedure for their integration into an overall vulnerability index with high spatial density represent the major analysis tool within the information system. The additional innovations of the information system include: 1) the computation of selected flood risk-vulnerability indicators organized into themes from four components of vulnerability to flood, i.e., physical, economic, infrastructure, and social vulnerability [15], 2) the spatial infrastructure vulnerability analysis to flood due to inundation of main communication routes and road bridges, 3) the spatial flood impacts due to inundation of critical facilities (schools, hospitals, and fire stations) and 4) quantification of exposures of land use/land cover and soil permeability to flood. The postal codes or Forward Sortation Areas (FSA) are considered for spatial discretization of the region and flood risk evaluation. An interactive analysis tool is also developed for calculation of flood risk as a function of change in land use. The proposed information system is implemented to six major damage centers in the Upper Thames River watershed, located in the South-Western Ontario, Canada. The study focuses only on floods which are caused by the overflow of river banks that are characteristics for the region of interest.

As a prerequisite, some relevant technical definitions are provided in the next section. The third section contains a detailed description of the study area-the Upper Thames River basin in South-Western Ontario, Canada. The fourth, fifth and sixth sections provide the details on determination of probability of occurrence, vulnerability and exposures of land use and soil permeability to flood, respectively; and summarize the results obtained. The seventh section describes the features of developed information system for risk-vulnerability analyses to flood. The eighth section summarizes the conclusions from the study.

\section{General Definitions}

The most common approach to define "flood risk" is the definition of risk as the product of "hazard", i.e., the physical and statistical aspects of the actual flooding (e.g., return period of the flood, extent and depth of inundation), and the "vulnerability", i.e., the exposure of people and assets to floods and the susceptibility of the elements at risk to suffer from flood damage $[7,47,48]$. This definition is adopted in the Flood Directive [49]. According to Forster et al. [44], flood risk is a combination of potential damage and probability of flooding. More precisely, risk is considered as the product of hazard and vulnerability of a region [47]. However, in this study flood risk is the product of probability of occurrence $\left(p_{e}\right)$, vulnerability to flood $(V)$, and exposures of land use $\left(E^{\text {Land }}\right)$ and soil permeability $\left(E^{\text {Soil }}\right)$ to flood, following 
the concept of Kron [50] and Barredo et al. [13], where flood risk is expressed as a function of the hazard, vulnerability and exposed values:

$$
\text { Flood Risk }=\left(p_{e}\right) \times(V) \times\left(E^{\text {Land }} \text { and } E^{\text {Soil }}\right)
$$

Hazard may be defined as a threatening event, or the "probability of occurrence $\left(p_{e}\right)$ " of a potentially damaging phenomenon within a given time period and area [31, 47]. It frequently encompasses hydrological and hydraulic analyses and the mapping of flood lines on floodplain. Vulnerability to flood $(V)$ is defined as a measure of a regions' or population susceptibility to flood damages [51-53]. Exposures of land use ( $\left.E^{\text {Land }}\right)$ and soil permeability $\left(E^{\text {Soil }}\right)$ to flood quantify their effect on the severity of flood. When the exposures of land use/land cover and soil permeability to flood are considered, these denote how land use and soil permeability affects the severity of flood. For example, urbanized land use pattern results in an impervious soil layer increasing the severity of flood and thus the exposure of land use pattern to flood in an urban area is high. The exposure of soil permeability to flood is also directly related to flood flow. The more permeable soil has more infiltration capacity and therefore reduces surface runoff, whereas less permeable soil has less infiltration capacity and is more prone to water logging [54].

In the present study, all the information on the above mentioned three components of flood risk are effectively presented and processed using GIS. The layout for collecting and integrating the data, along with the sequential procedural steps for data processing and representation are outlined in Figure 1. The vulnerability section in Figure 1, illustrates the concept of layering data using a GIS, as well as combining vulnerability components to assess the overall vulnerability to flood. The next section presents the detailed characteristics and geography of the study area.

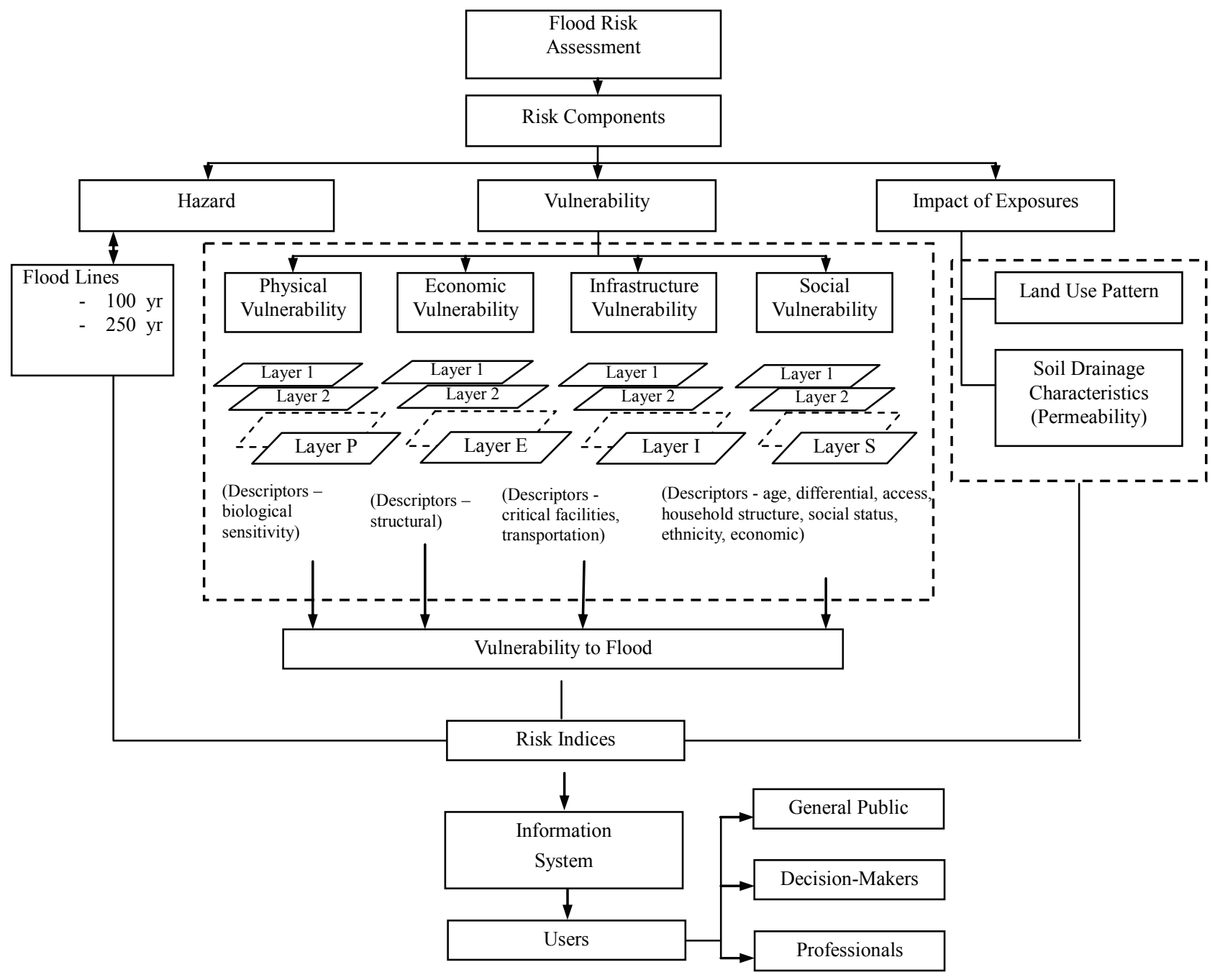

Figure 1. Organization of the flood information system. 


\section{Study Area}

The Upper Thames river basin lies in the middle of south western Ontario; drains an area of $3,500 \mathrm{~km}^{2}$; and is populated by approximately 422,000 people. The basin is nested between the Great Lakes Huron and Erie. The basin has a well documented history of flooding events dating back to the 1700s. A detailed map of the Upper Thames River watershed in Ontario, Canada with a location map (inset) is shown in Figure 2. Two main tributaries of the Thames River, referred to as the North $\left(1,750 \mathrm{~km}^{2}\right)$ and South $\left(1,360 \mathrm{~km}^{2}\right)$ branches, join at a location in London known as "The Forks" (Figure 2). The Forks region has served as a historical landmark for London, and is characterized by both commercial and residential structures. Major flood damage centers in the watershed include communities of London, St. Marys, Ingersoll, Mitchell, Stratford and Woodstock. The Upper Thames river basin is an area of special importance for the sustainable socio-economic development of Ontario. This is a large and fertile area, and plays an important role in agriculture production from, fishing and aquaculture to perennial fruit trees. The flooding in the Upper Thames river watershed has the great effect on the fertility of soil and increase in the natural aquatic production. It is also the most dangerous natural disaster hazard affecting the socio-economic development and the life of the people in the area. Several studies have already been done to estimate the economic damage in the watershed due to flooding [55].

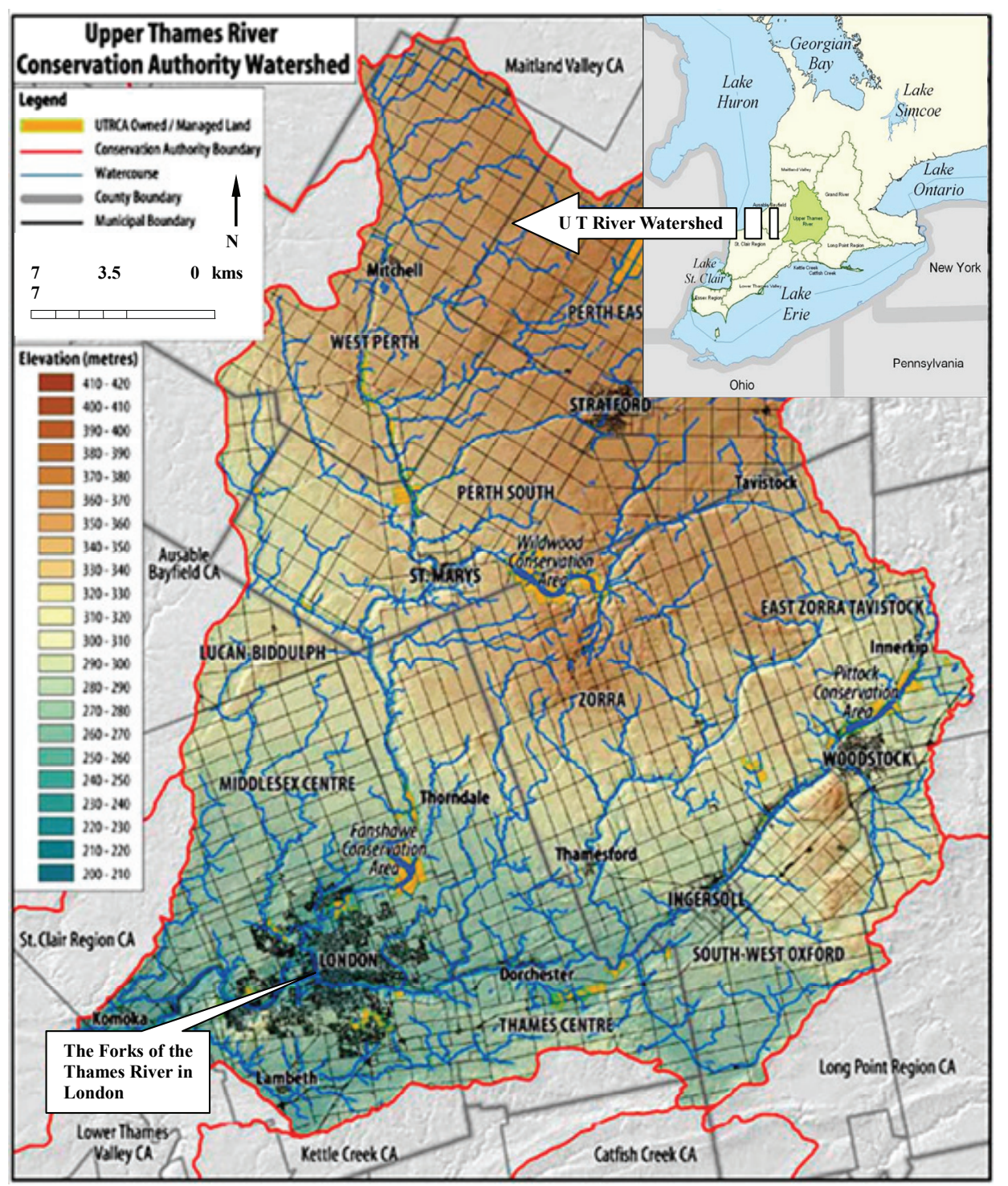

Figure 2. Detailed map and location map (inset) of the Upper Thames River watershed (Source: <http://www.thamesriver.on.ca/About_Us/images/UTRCA_Watershed.jpg>). 
The study area consists of a number of major postal code regions, some of which extend beyond the watershed bo- undaries. The Forward Sortation Areas (FSAs) are distinguished by the first three characters of their postal code designation. The regions which historically experience more frequent flooding events are selected as areas of particular significance and the FSAs of these regions are selected for analysis. A total of 25 FSAs from these cities have been considered in the study, and are listed in Table 1. These FSAs are the smallest spatial geographic units considered in this study. The cities of important FSAs include London (17 FSAs), Woodstock (3 FSAs), Mitchell (1 FSA), St. Marys (1 FSA), Ingersoll (1 FSA) and Stratford (2 FSAs); with a particular emphasis on the city of London. Table 1 shows that the largest FSA by area in London is N6P; with an area of $103 \mathrm{~km}^{2}$ and in the entire study area is NOK; with an area of $1510.0 \mathrm{~km}^{2}$. The smallest FSA by area in London is N6B; with an area of $3.2 \mathrm{~km}^{2}$, and in the entire study area is N4Z; with an area of $0.5 \mathrm{~km}^{2}$. The average area of an FSA in London is $29.5 \mathrm{~km}^{2}$ and the average area of all FSAs in the study area is $122.2 \mathrm{~km}^{2}$.

Numerical data necessary for the development of a flood information system has been collected from Statistics Canada, which provides updated national statistics consistently every five years following a Census of the population. Data is available for areas of various sizes, including FSAs as small census divisions which remain relatively stable over many years. Various layers and datasets compatible with the GIS software are collected from Statistics Canada, The Ontario Fundamental Dataset, Upper Thames River Conservation Authority (UTRCA), Surficial Geology of Southern Ontario (SGSO) dataset, and Route Logistics (RL). These datasets are available online or obtained from the Serge A. Sawyer map library and the Internet Data Library System (IDLS) at the University of Western Ontario (UWO), London, Canada. Table 2 presents the detailed information on different data layers with their formats and sources used in the present case study. All three components of the flood risk are assessed and represented in the information system separately in dissimilar ways. Each component is represented graphically, numerically, or using a combination of both. Next two sections describe the methodologies for determination of probability of occurrence and vulnerability to flood.

\section{Probability of Occurrence}

Probability of occurrence of flood $\left(p_{e}\right)$ [31] describes a physical threat from a flood occurring and a region becoming inundated. The consideration of probability of occurrence as a flood risk component is essential, since flood
Table 1. List of the municipalities and FSAs (PSEPC* 2005).

\begin{tabular}{cccccc}
\hline Municipality & FSA & $\begin{array}{c}\text { Area } \\
\left.\text { (in } \mathrm{km}^{2}\right)\end{array}$ & Municipality & FSA & $\begin{array}{c}\text { Area } \\
\left.\text { (in km }{ }^{2}\right)\end{array}$ \\
\hline \multirow{6}{*}{ London } & N5V & 46.7 & & N6L & 38.0 \\
& N5W & 15.7 & London & N6M & 28.7 \\
& N5X & 27.0 & & N6N & 70.0 \\
& N5Y & 10.0 & & N6P & 103.0 \\
& N5Z & 11.0 & Mitchell & N0K & 1510.0 \\
& N6A & 7.1 & & N4S & 326.0 \\
& N6B & 3.2 & Wood- & N4T & 4.1 \\
& N6C & 13.5 & Stock & N4V & 2.1 \\
& N6E & 20.6 & St. Marys & N4X & 327.0 \\
& N6G & 25.8 & Stratford & N4Z & 0.5 \\
& N6H & 41.5 & & N5A & 233.0 \\
& N6J & 12.0 & Ingersoll & N5C & 149.0 \\
\hline & N6K & 28.4 & & \\
\hline
\end{tabular}

*Public Safety and Emergency Preparedness Canada.

Table 2. Information on data layers used in GIS.

\begin{tabular}{cccc}
\hline Indicator & Source* & Layer & Type \\
\hline Wetlands & OFD & wetlands_unit & Polygon \\
Roads & OFD & road & Line \\
Railways & OFD & transport_line & Line \\
Unpaved roads & OFD & road & Line \\
Intersections & RL & ren & Point \\
Critical facilities & OFD & building_symbol & Point \\
Bridges & RL & rll & Line \\
Land use & RL & ONland_use & Polygon \\
Soil permeability & SGSO & sgu_poly & Polygon \\
100-year flood line & UTRCA & -- & Line \\
250-year flood line & UTRCA & -- & Line \\
Grid & BM & obmindex & Polygon \\
FSAs & RL & zip & Polygon \\
\hline
\end{tabular}

*OFD - Ontario Fundamental Dataset (OGDE-Alymer_Guelph.mdb) from the Serge A. Sauer Map Library at UWO; RL-CanMaps Route Logistics, 2006 dataset from the UWO IDLS; SGSO-Surficial Geology of Southern Ontario, 2003 cd-rom dataset from Serge A. Sauer Map Library aUWO; UTRCA - the layers obtained from the Upper Thames River Conservation Authority in 2007; BM-Ontario Base Map Sheet, 2001 from the UWO IDLS.

risk of a highly vulnerable population to flood is negligent if there is less probability or chance of occurrence of flood. The probability of occurrence (i.e., the extreme events and associated probability) of flood is also termed as "flood hazard" by many researchers $[7,13,47,50,56]$. In the present study however, the available results on $p_{e}$ performed by the UTRCA are used. Already available 100 -year and 250-year flood lines are used for risk-vulnerability analysis. 
The probability or likelihood of occurrence of flooding is described as the chance that a location will be flooded in any one year. For example, $1.3 \%$ chance of flooding each year implies 1 in 75 chance of flooding at that location in any year. Exceedance probability $\left(p_{e}\right)$ of a flood is represented as $[31,57]$ :

$$
P[X \geq x]=p_{e}=1-F(x)
$$

where $F(x)$ denotes the value of Cumulative Distribution Function $(\mathrm{CDF})$ of river flow $x$. The return period $\left(T_{x}\right)$ of flood flow $x$ is the reciprocal of exceedance probability, which is mathematically represented as [57]:

$$
T_{x}=1 / P[X \geq x]=1 /[1-F(x)]
$$

A flood line of a particular return period is the extreme boundary of the region exposed to a flood of the same return period. It represents the spatial extent of threat from the flood of a particular return period. The flood lines for a particular return period are evaluated by using physical, hydraulic and hydrologic characteristics of a particular location in the watershed. The present study utilizes 250year flood line data for all FSAs being considered and 100-year flood line data for FSAs within the City of London, as per the availability. A flood hazard map with 100 and 250-years flood lines is used as one of risk components depicting spatial extent of flooding with exceedance probability of 0.01 and 0.004 , respectively. The following procedural steps are followed in GIS for incorporating the information on probability of occurrence in this study: 1) the FSA, 100 and 250-years flood line shapefile layers are imported into ArcMap [58]; 2) the FSA layer and 100-yr flood line layers are turned "on" so that they are displayed in the Data Viewing window; 3) twenty five FSAs of interest in this study are highlighted using the selection tool and then converted into their own layer (FSA layer of interest); 4) these map features are then observed in the "layout" view where it is possible to insert map elements such as north arrows, legends and scale bars using the Insert Map Elements feature; 5) the map is then exported to ".jpeg" format. The same procedure is repeated for the 250 -year flood line layer.

\section{Vulnerability to Flood}

Vulnerability to flood is defined as measure of a region's susceptibility to flood damage [51-53]. It also includes population susceptibility to physical, mental or emotional damage due to flooding. Vulnerability could be influenced by individual emotions, seriousness of the current situation, and previous experiences with natural disasters. Traditionally, vulnerability has considered only biophysical factors. More recently, social factors have also been incorporated into assessment of vulnerability to disasters [31].

In this study, vulnerability to flood has been defined as a combination of four distinctive types of vulnerabilities: physical, economic, infrastructure and social [15]. The physical vulnerability generally incorporates only those indicators susceptible to biological sensitivity. Wetlands are for example, considered regions of physical vulnerability in this study. Wetlands are among the most productive ecosystems on earth. The richness of these transitional ecosystems relates mostly to the diversity of ecological niches created by the variability of seasonal and interannual cycles. Modifications in the hydrologic regime that disturb these cycles have been found to be the main stress factor threatening shoreline wetlands in all the world's major rivers [59]. The regulation of water levels has also caused the shrinkage of wetlands, and an incidental reduction in the diversity of plant communities and the number of plant species [60]. These regions have high biodiversity and sensitive life, which would experience higher damages, longer, slower recovery times due to flooding. Economic vulnerability includes flood damage indicators which can be expressed in monetary terms. Infrastructure vulnerability includes civil structure such as road networks, railways, and road bridges. Infrastructure components are important to movement of population, communications, and safety. Their inundation impedes traffic and hinders communications, increasing stress in the exposed population. Inundation may also block important emergency routes and cause physical damage to roads. Social vulnerability focuses on the reaction, response, and resistance of a population to a disastrous event. Vulnerable population may require special attention in an evacuation situation for example. The indicators are chosen based on a review of existing literature assessing vulnerability to current hazards [25-27, 31,32,51].

The vulnerability index $\left(V I_{i}\right)$ corresponding to each indicator for $i^{\text {th }}$ FSA is calculated using the following equation, which standardizes [61] each vulnerability index value ranging from 0.0 to 1.0 as done by $\mathrm{Wu}$ et al. [51]:

$$
V I_{i}=\frac{V_{i}-V^{\min }}{V^{\max }-V^{\min }}
$$

where $V^{\min }$ and $V^{\max }$ are the minimum and maximum values of the indicator for all FSAs, respectively, and $V_{i}$ is the actual value of the indicator for $i^{\text {th }}$ FSA. All physical, economic, infrastructure (including the numbers of critical facilities and road bridges) and social vulnerability indices are directly calculated using (4). For example, vulnerability index for $i^{\text {th }}$ FSA of the social vulnerability indicator "Population under 20yrs of age" is calculated from the data set of 25 values (for 25 FSAs) on population under 20yrs of age using (4). The GIS is not used for determination of economic and social vulnerability indices, as they are directly calculated in the spreadsheet using Statistics Canada Census data. The economic and so- 
cial vulnerability maps are created in ArcMap on the basis of calculated values of vulnerability indices. The following procedure is followed for calculating the sum of the length of roadways/railways: 1) roads/railways layer is imported into GIS; 2) the length of each $\mathrm{road} / \mathrm{railway}$ is contained in the attributes table; 3 ) those $\mathrm{road} / \mathrm{railway}$ segments from the attribute table are selected which fall within and intersect a particular FSA; 4) the "statistics" option from the "length" field in the attribute table options is selected; 5) the program calculates the sum of lengths and display them in that particular FSA; 6) the values are stored in a table and finally 4) is used for determining the vulnerability indices_- "length of roads" and "length of railways". The similar procedure is followed for the vulnerability index- "unpaved roads", but the unpaved, dirt and gravel roads are selected for each FSA individually using the "Select by Location" or "Select by Attributes" tool.

This calculation of vulnerability index using 4) [61] offers an improvement over the traditional calculation [26,31,51] of vulnerability index, i.e., dividing all values by the maximum value, $V I_{i}=\left(V_{i} / V^{\max }\right)$, as it considers

both the maximum and minimum values and ensures that the vulnerability indices are within $[0,1]$ interval and always non-negative. It is not necessary to use the scale $[0,1]$ for standardization. Montz and Evans [25], Grosshans et al. [54] and Odeh et al. [62] standardize the values of vulnerability and plotted the maps considering $[0,10],[0,5]$ and $[0,100]$ scales, respectively. In the assessment of infrastructure vulnerability, the present study considers: a) the impact of flooding of critical facilities (schools, hospitals, and fire stations) and b) the spatial impact of flooding of main communication routes and road bridges. The developed methodologies for considering these impacts are discussed in next two subsections. The main objectives of the analysis presented in these two subsections are: 1) to model the impact of inundation of critical facilities (e.g., schools, hospitals and fire stations) of an FSA on its total infrastructure vulnerability, which is achieved by considering the "number of critical facilities (i.e., number of schools or hospitals within an FSA)" as vulnerability indicators [determined by using 4), as done for physical, economic, social and other infrastructure vulnerability indicators]; and 2) to model the impact of inundation of an FSA (which may contain one or more than one critical facilities) on its surrounding FSAs, which is modeled using a grid system. There are numerous studies that have addressed the impact of inundation of critical facilities on infrastructure vulnerability based on the number of critical facilities within an FSA $[27,51,62]$, but none that explore the impact on surrounding FSAs, because people dwelling outside the flooded FSA also may depend on the critical facilities situated within the flooded FSA. This impact on infrastructure vulnerability of surrounding FSAs is mod- eled using a grid system.

\subsection{Infrastructure Vulnerability Due to Inundation of Critical Facilities}

Vulnerability of critical facilities is an indicator of infrastructure vulnerability [27,51,62]. Emergency shelters, nursing homes, public buildings, schools, hospitals, fire and rescue stations, police stations, water treatment or sewage processing plants, utilities, railroad stations, airports and government facilities are identified as critical facilities by Odeh et al. [62] and Flax et al. [27]. Critical facilities are those that play an integral role in public safety, health, and provision of aid [27]. As per the availability of data, the critical facilities considered in this study include schools, fire stations and hospitals, and are given special attention in vulnerability analysis in order to provide a more accurate estimate of flood risk.

Schools can be used for both education and as a place of refuge and a center for aid distribution during a flood. Fire stations provide the source of response to an emergency in the area near the station, and aid in disaster relief. Flooding of a fire station causes the population in close proximity to be more vulnerable. Hospitals represent another type of critical facilities that require special attention during flooding. Hospitals may have patients that need special attention in the case of an emergency. Procedure for assessment of infrastructure vulnerability due to inundation of critical facilities includes the use of a GIS tool. As per the availability of data, the FSAs of London are considered for the demonstration of the methodology. The impact of inundation of critical facilities of an FSA on its total infrastructure vulnerability is determined by considering the "number of critical facilities (i.e., number of schools or hospitals within an FSA)" as vulnerability indicators [determined by using 4), as done for physical, economic, social and other infrastructure vulnerability indicators]. To model the impact of inundation of an FSA (which may contain one or more than one critical facilities) on its surrounding FSAs, a $6 \times 6$ grid layer is placed over the FSAs of London, which breaks the entire city into 36 cells, as illustrated in Figure 3(a). The size of each grid cell is $25 \mathrm{~km}^{2}(5 \mathrm{~km} \times 5$ $\mathrm{km})$. The cell area for each FSA is calculated using area calculation function provided by the GIS tool. The layer containing the information on critical facilities is placed onto the grid layer and FSA layer to determine areas more susceptible to damage. The process used in assigning infrastructure vulnerability due to the inundation of critical facilities is based on the assumption that the people closest to the facility are its primary users. Thus, the spatial shape, termed as "vulnerability shape" in this study, is square as shown in Figure 3(b). There are four different color designations (red, orange, yellow and white) representing assigned Degree of Importance (DI). 
The presence of just one of these is sufficient to classify the cell as important. All "important" cells are equally important. The DI values indicating vulnerability levels decrease equally in all directions with the distance from the inundated cell. Procedure implemented using GIS tool is as follows:

1) Divide the area under consideration into a grid - the grid should be regular in shape. In this analysis, a $6 \times 6$ square grid is used for demonstration purpose.

2) Use the DI to quantify the importance of a critical facility for each FSA. Red, orange, yellow and white color codes correspond to $1.0,0.75,0.2$ and 0.0 DI values, respectively. The colors are reflecting the DI of each cell: red (high), orange (medium), yellow (low), white (no influence), which indicates the importance of the presence of critical facilities. The grid cells within an FSA that contain one or more critical facilities are identified. These grid cells are assigned red color, the highest DI of 1 , assuming that the people closest to the facility are its primary users.

3) Assign a white color, indicating "zero" DI value to the remaining grid cells. The result is a square-shaped representation of vulnerability, which decreases with distance from the red (center) cell.

4) Following the previous three steps, assign DI values for all grid cells separately for each case of a grid cell with red color. For example, if 10 (ten) grid cells contain critical facilities, the grids cells would be assigned appropriate DI values 10 times. Finally, the Overall DI (ODI) for a grid cell is calculated by averaging these ten DI values.

5) The vulnerability for an FSA - area shown in bold solid line in Figure 3(c) - is calculated as:

$$
V u l_{e_{i}} \text { of } \mathrm{i}^{\text {th }} \mathrm{FSA}=\sum_{j=1}^{k}\left(O D I_{k} \times A_{k}\right) / \sum_{j=1}^{k} A_{k}
$$

where $O D I_{k}$ is overall DI for $\mathrm{k}^{\text {th }}$ grid cell, $A_{k}$ is the area of $i^{\text {th }}$ FSA.

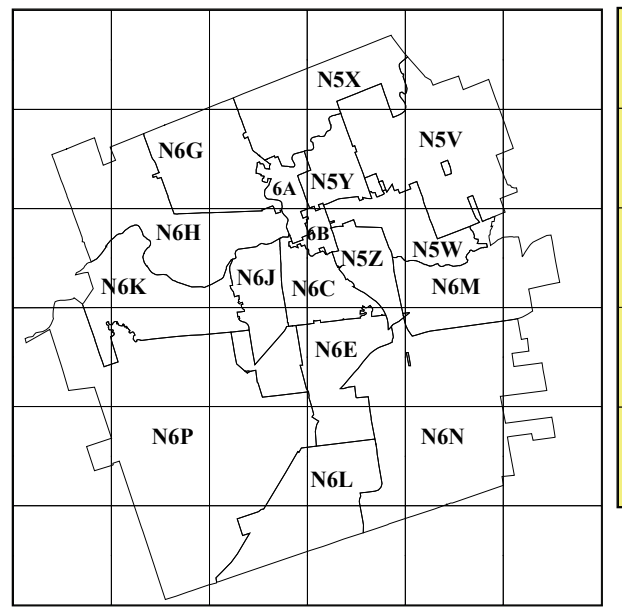

(a)

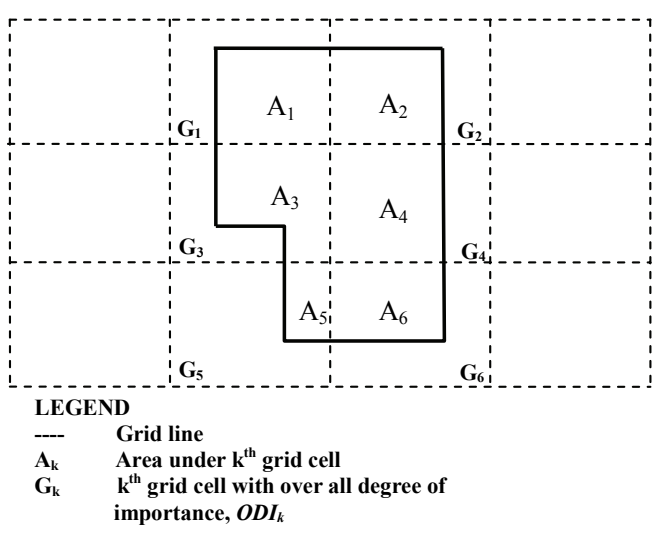

(c)

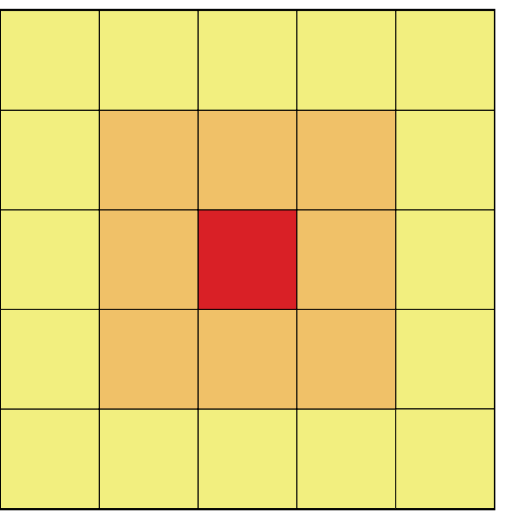

(b)

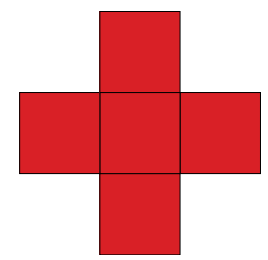

(d)

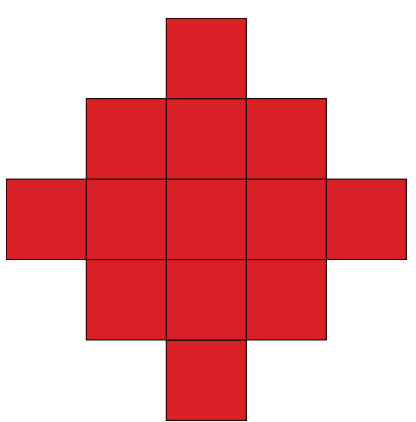

(e)

Figure 3. Determination of the vulnerability due to inundation of critical facilities and bridges. (a) $6 \times 6$-grid layered over the FSAs of London; (b) square vulnerability shape; (c) example FSA region divided in grid cells; (d) vulnerability shapes for cells with 1-5 bridges; (e) with 6-10 bridges (not to scale). 
6) Determine the standardized vulnerability index value using:

$$
V u l_{e_{i}}^{s t d}=\frac{V u l_{e_{i}}-V u l_{e}^{\min }}{V u l_{e}^{\max }-V u l_{e}^{\min }}
$$

where $\mathrm{Vul}_{e}^{\max }$ and $V u l_{e}^{\min }$ are the maximum and minimum vulnerability values of critical facilities, $V u l_{e_{i}}$ is the

value of vulnerability for critical facilities pertaining to the $\mathrm{i}^{\text {th }}$ FSA. Thus the standardized infrastructure vulnerability values are obtained at FSA level.

\subsection{Infrastructure Vulnerability Due to Inundation of Road Bridges}

The infrastructure vulnerability is also affected by the inundation of road bridges. Vulnerability of an area due to the inundation of a bridge includes the interruption of traffic and formation of communication barriers between different locations in the affected region. Inundation of, or damage to a particular bridge affects not only the FSA in which it is located, but also all other FSAs that depend on the use of the bridge. In this study, only bridges over the water bodies are considered significant, because these bridges have limited alternate routes associated with them, and are necessary for safe crossing of the water body. They are frequently used as means for transporting commercial goods, a route to and from the workplace, and as emergency routes in case of a disaster.

The impact of inundation of road bridges of an FSA on its total infrastructure vulnerability is modeled by considering the "number of road bridges" as vulnerability indicator [determined by using 4), as done for physical, economic, social and other infrastructure vulnerability indicators]. To model the impact of inundation of an FSA (which may contain one or more than one road bridges) on its surrounding FSAs, the same procedure (steps 1 through 6) as described in previous subsection is followed, with the use of the new vulnerability shapes as shown in Figures 3(d) and (e). Again, $6 \times 6$ grid is used in the assessment of vulnerability as shown in Figure 3(a). However, the shape used in assessing vulnerability due to the inundation of road bridges is not a box, but rather cross-like. The shape varies with the number of bridges in any particular grid cell. Figures 3(d) and (e) illustrate the shapes of vulnerability for cells containing 1-5 and 6-10 road bridges, respectively. The number of bridges over water that is contained in each cell determines the shape that would be used in assessment of vulnerability. As the number of bridges increases, the more likely it is that inundation of that cell would affect more people. The vulnerability shape due to inundation of bridges is mainly based on a basic assumption: the need for crossing any given bridge decreases with distance from the bridge (i.e., the need for crossing the bridge is highest in areas that are closest to the bridge), because people further away from a particular bridge may have other alternatives for crossing the water body with equal convenience. The proposed method assumes that the whole cell being considered is flooded, and that bridges in that cell are unavailable for use. The cells are assigned a DI based on the vulnerability mapping in proximity to the inundated cell. The DI assignment is similar to the one used in assessing the infrastructure vulnerability due to inundation of critical facilities. However, the road bridges scenario designates a DI as either red/high (1.0) or yellow/low (0.2) for demonstration of the proposed methodology. In both analyses it was assumed that the whole grid cell is equally affected by the flooding, thus damage is assumed to be uniform across the cell area. The population density within a portion of the FSA covered by a grid cell is not known. Therefore a uniform distribution of population is assumed throughout each FSA.

The following procedural steps are followed in GIS for incorporating the information on infrastructure vulnerability due to inundation of critical facilities: 1) the "buildings" layer is imported; 2) in the attribute table the type of building is specified. In the options for the attribute table "select by attribute" is used and then the category (e.g., school/hospital/fire station) is used to select only those buildings which are schools/hospitals/fire stations; 3 ) these buildings are saved as a separate layer for referencing in the critical facilities analysis of the study. The same procedure is followed for road bridges but the "bridge" layer is imported.

The calculation of the vulnerability indices following the procedures described in this section provides input for mapping each category of vulnerability in GIS. Table 3 shows the values of four components of vulnerability in the Upper Thames River basin. The seventh column of Table 3 indicates the standardized average vulnerability values of four vulnerability components (presented in columns 3-6) for all FSAs. In physical vulnerability, the FSA-NOK in Michell is identified as the most vulnerable due to large wetland areas in the region. The FSAs with "zero" values in the column of physical vulnerability indicate absence of wetlands. The FSA-N4S in Woodstock is the most vulnerable in economic sense due to the presence of large number of older houses in this region. The FSA-NOK in Michell is also identified as the most vulnerable in regards to infrastructure component due to its largest land area, which includes the longest road and railway networks. It is also identified that the FSA-N4Z in Stratford is the least vulnerable due to the absence of railway and minimum length of paved and unpaved roads. The column for social vulnerability shows high values for most of the FSAs within the city of London due to high population in these FSAs. The FSA-N5Y is the most vulnerable in social sense due to high values of indicators such as "differential access to resources", "so- 
cial status" and "ethnicity".

The present study incorporates a unique consideration of inundation of road bridges and critical facilities in assessing infrastructure vulnerability.

Figure 4 displays the difference in infrastructure vulnerability due to inundation of critical facilities and road bridges. In most cases, the standardized values of infrastructure vulnerability of the FSA increase with the addition of impacts due to the inundation of road bridges and critical facilities. The GIS generated map may be produced for each component of vulnerability values as presented in Table 3 for identifying spatial variability of vulnerabilities to flood. More details of the processed numerical data and graphical results of the present vulnerability analysis to flood can be obtained from Peck et al. [63].

\subsection{Calculation of the Vulnerability to Flood}

Although maps of individual component of vulnerability can be useful, it is easiest to assess vulnerability throughout the watershed if the multidimensional components can be integrated into a single measure [32]. In the present study, the simplest way to combine the four components of vulnerability into a single measure would be to average the values of indices [31,51] for each component [as given in the seventh column of Table 3]. Figure 5 shows the GIS generated map of vulnerability to flood obtained by averaging and standardizing the four components of vulnerability. The darker color indicates larger vulnerability. Map in Figure 5 provides for easy comparison of vulnerability between different FSA regions of six major damage centers, and insight into the spatial
Table 3. Vulnerability analysis to flood of the Upper Thames River basin.

\begin{tabular}{|c|c|c|c|c|c|c|c|}
\hline \multirow{2}{*}{$\begin{array}{l}\text { Damage } \\
\text { Center }\end{array}$} & \multirow{2}{*}{ FSA } & \multicolumn{4}{|c|}{$\begin{array}{c}\text { Components of Vulnerability } \\
\text { to Flood }\end{array}$} & \multirow{2}{*}{$\begin{array}{l}\text { Overall } \\
\text { vul* }\end{array}$} & \multirow{2}{*}{ Rank } \\
\hline & & Phy. & Eco. & Infras. & Soc. & & \\
\hline \multirow{17}{*}{ London } & N6A & 0.000 & 0.264 & 0.432 & 0.383 & 0.296 & 15 \\
\hline & N6B & 0.000 & 0.282 & 0.467 & 0.399 & 0.316 & 12 \\
\hline & N6C & 0.014 & 0.613 & 0.477 & 0.794 & 0.498 & 6 \\
\hline & N6E & 0.000 & 0.128 & 0.256 & 0.767 & 0.303 & 13 \\
\hline & N6G & 0.000 & 0.495 & 0.556 & 0.703 & 0.471 & 9 \\
\hline & $\mathrm{N} 6 \mathrm{H}$ & 0.015 & 0.828 & 0.356 & 0.784 & 0.503 & 5 \\
\hline & N6J & 0.000 & 0.876 & 0.447 & 0.732 & 0.296 & 14 \\
\hline & N6K & 0.004 & 0.457 & 0.299 & 0.613 & 0.527 & 4 \\
\hline & N6L & 0.000 & 0.000 & 0.022 & 0.000 & 0.353 & 11 \\
\hline & N6M & 0.009 & 0.234 & 0.172 & 0.012 & 0.000 & 25 \\
\hline & N6N & 0.044 & 0.004 & 0.055 & 0.020 & 0.110 & 19 \\
\hline & N6P & 0.005 & 0.084 & 0.089 & 0.072 & 0.032 & 22 \\
\hline & N5V & 0.002 & 0.815 & 0.305 & 0.813 & 0.061 & 20 \\
\hline & N5W & 0.000 & 0.515 & 0.421 & 0.608 & 0.486 & 8 \\
\hline & N5X & 0.034 & 0.288 & 0.293 & 0.390 & 0.405 & 10 \\
\hline & N5Y & 0.001 & 0.707 & 0.461 & 1.000 & 0.268 & 16 \\
\hline & N5Z & 0.005 & 0.539 & 0.502 & 0.736 & 0.562 & 3 \\
\hline Michell & NOK & 1.000 & 0.749 & 1.000 & 0.632 & 1.000 & 1 \\
\hline \multirow{3}{*}{ Wood-stock } & N4S & 0.000 & 1.000 & 0.510 & 0.715 & 0.572 & 2 \\
\hline & $\mathrm{N} 4 \mathrm{~T}$ & 0.000 & 0.110 & 0.011 & 0.082 & 0.041 & 21 \\
\hline & $\mathrm{N} 4 \mathrm{~V}$ & 0.004 & 0.027 & 0.008 & 0.030 & 0.010 & 23 \\
\hline St. Marys & $\mathrm{N} 4 \mathrm{X}$ & 0.002 & 0.266 & 0.299 & 0.181 & 0.200 & 18 \\
\hline \multirow{2}{*}{ Stratford } & $\mathrm{N} 4 \mathrm{Z}$ & 0.000 & 0.048 & 0.000 & 0.021 & 0.009 & 24 \\
\hline & N5A & 0.134 & 0.673 & 0.384 & 0.690 & 0.494 & 7 \\
\hline Ingersoll & $\mathrm{N} 5 \mathrm{C}$ & 0.092 & 0.293 & 0.275 & 0.261 & 0.249 & 17 \\
\hline
\end{tabular}

*Overall vulnerability: standardized average values

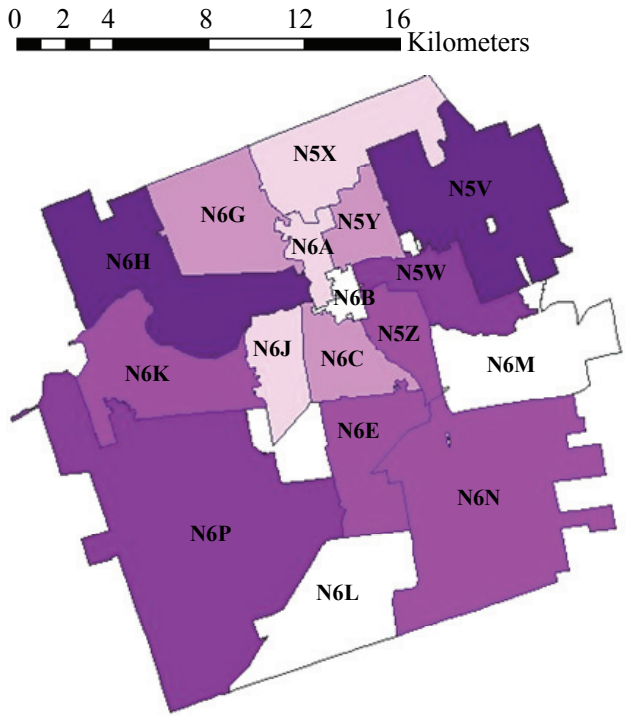

(a)

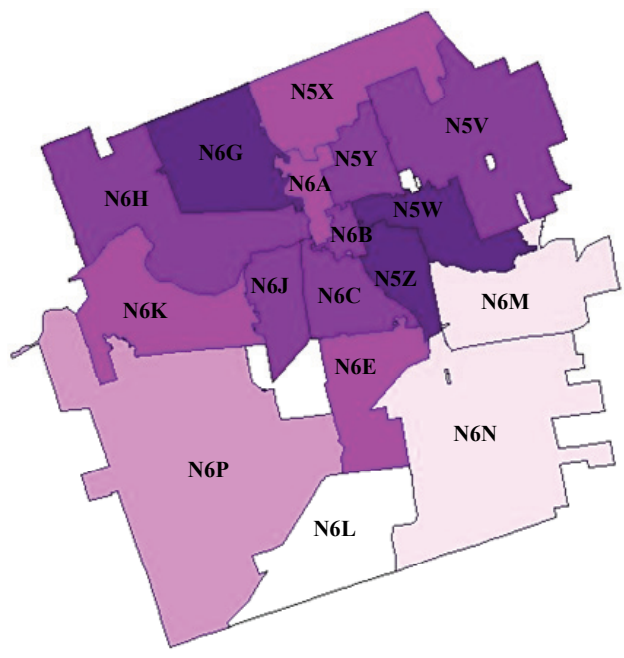

(b)

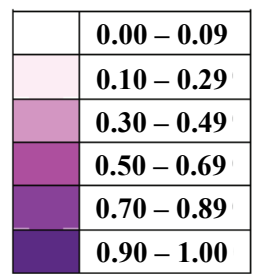

Figure 4. Infrastructure vulnerability for the FSAs of London. (a) infrastructure vulnerability not considering the impact of critical facilities and bridges; (b) infrastructure vulnerability including the critical facilities and bridges. 
variability of vulnerability. It is identified from Table 3 and Figure 5 that FSA-NOK in Michell is the most vulnerable in the basin, as the area under this postal code is much larger than other FSAs and consequently it contains a number of wetlands and more infrastructure. It is found that the vulnerability values for FSAs in London vary between 0 and 0.562 . The FSA-N5Z is identified as the most vulnerable, whereas $\mathrm{N} 6 \mathrm{M}$ is identified as the least vulnerable within the city of London. The Table 3 and Figure 5 give a general description of region's vulnerability, and can be used for emergency flood management, disaster mitigation activities and planning future disaster protection infrastructure.

It should be noted for clarification that, there may be some correlation among vulnerability indicators under different components of vulnerability. In this study the chance of involving correlated indicators is very less, as the indicators are chosen based on a review of existing literature $[25-27,31,32,51]$. If the number of indicators is too high Principal Components Analysis (PCA) [32] can be applied to select the set of uncorrelated indicators. The basic aim of a PCA is to reduce a complex set of many correlated variables into a set of fewer, uncorrelated components.

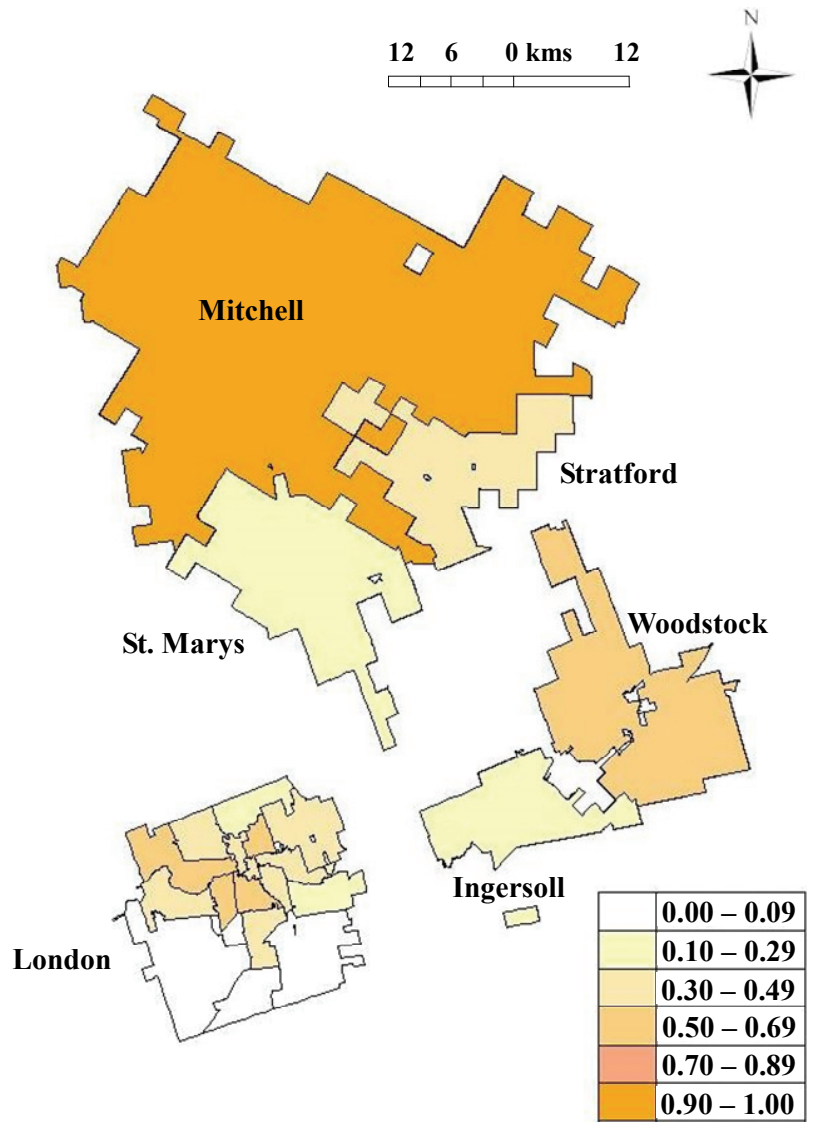

Figure 5. GIS generated map of standardized average vulnerability to flood.

\section{Exposures of Land Use and Soil Permeability to Flood}

The present study utilizes 250-year flood line data for all FSAs and 100-year flood line data for FSAs within the City of London, as obtained from UTRCA, Canada, for considering the values of probability of occurrence in the calculation of flood risk. The impacts of land use and soil type are not considered during generation of the flood lines and probability of occurrences. To incorporate the impact of exposures of land use and soil permeability into the analysis a separate component of the flood risk is considered as expressed in (1), following Kron [50] and Barredo et al. [13]. The indices of vulnerability to flood, as discussed in previous section, have no influence on flood flow and river channel characteristics. The exposures of land use and soil permeability are two physical watershed characteristics which affect the flood flow [64], and are considered as the important characteristics of flood risk in the Upper Thames River watershed. This study considers the impact of exposures of land use and soil permeability only for those FSAs within the municipality of London as per the availability of data. An exposure value of 1 is assigned to the regions outside of the City of London.

\subsection{Land Use}

The land use map used in the present study is obtained from the UWO Internet Data Library System (IDLS). Their CanMap Route Logistics 2006 dataset contains the Ontario land use GIS layer. This layer is designated as "ONland_use" and is of type "polygon" as mentioned in Table 2. The available land use data include seven different categories of use: open space, commercial, residential, parks and recreational, government and institutional, resource and industrial, and water body. Each of these land use categories has been assigned a DI value. These values, while estimated by the research team, can be changed by decision-makers with more extensive knowledge on how different land use influences flood runoff characteristics. Overdeveloped and highly commercialized areas include more pavement and impervious surfaces. They increase runoff quantity and shorten the time of concentration. On the other side, open land (including agricultural land) is exposed to direct infiltration of rainfall which decreases runoff quantity and lengthens the time of concentration. With this knowledge, the DI values are assigned to each category of land use, which are as follows: water body $(0.1)$, parks \& recreational $(0.2)$, open area $(0.3)$, Government and institutional (0.7), commercial $(0.8)$, residential $(0.8)$, resources \& industrial $(0.8)$.

Area under each land use type is expressed as a fraction of the FSAs total area. Summation of the fraction of 
each type multiplied by its DI provides an exposure value representative of the land use for an FSA. Therefore, mathematically the exposures of land use to flood for $\mathrm{i}^{\text {th }} \mathrm{FSA}$ is expressed as:

$$
E_{i}^{\text {Land }}=\sum_{l=1}^{n}\left[D I_{l} \times\left(A_{i}^{l} / A_{i}\right)\right]
$$

where $E_{i}^{\text {Land }}$ is the exposure of land use to flood, $D I_{l}$ is the DI of land use type "l". "l" may be any of the land use types. Area under each land use type 1 is expressed as $A_{i}^{l}$ for $\mathrm{i}^{\text {th }}$ FSA. Total area of the $\mathrm{i}^{\text {th }}$ FSA is denoted as $A_{i}$.

\subsection{Soil Permeability}

Soil permeability refers to the hydrological drainage characteristic of soil to allow water movement through its pores, which is inversely proportional to soil density. The more permeable the soil is, the more water can be transmitted through it. A soil with low permeability, such as clay, doesn't permit much water flow. This could cause "puddling" of water and thus higher accumulation of water on the soil surface. Regions which are composed primarily of these types of soils are prone to a higher flood risk because the water requires a longer time to drain or infiltrate into the ground [54]. Using a GIS dataset known as Surficial Geology of Southern Ontario, it was possible to spatially assess the soil permeability characteristics of the region. The data is available with different designations of permeability: low, medium-low, high or variable. A DI is assigned to each permeability category based on the ability of soil to infiltrate water, facilitate its transmission, and decrease flooding. DI values assigned to each category of soil permeability are as follows: low (0.8), low-medium (0.6), variable $(0.5)$, high (0.3).

Area under each permeability category is expressed as a fraction of the FSAs total area. Summation of the fraction of each category multiplied by its DI provides an exposure value representative of soil permeability for an FSA. Therefore, mathematically the exposure of soil permeability to flood for $\mathrm{i}^{\text {th }} \mathrm{FSA}$ is expressed as:

$$
E_{i}^{\text {Soil }}=\sum_{p=1}^{m}\left[D I_{p} \times\left(A_{i}^{p} / A_{i}\right)\right]
$$

where $E_{i}^{\text {Soil }}$ is the exposure of soil permeability to flood, $D I_{P}$ is the DI of permeability category "p". "p" may be low, medium-low, variable and high. Area under each permeability category (p) is expressed as $A_{i}^{p}$ for $\mathrm{i}^{\text {th }}$ FSA. Total area of the $\mathrm{i}^{\text {th }}$ FSA is denoted as $A_{i}$. The standardization is being performed following the equation similar to (4) and (6), expressed as:

$$
E_{i}^{s t d}=\frac{E_{i}-E^{\min }}{E^{\max }-E^{\min }}
$$

where $E^{\max }$ and $E^{\text {min }}$ are the maximum and minimum ex- posure values pertaining to land use/soil permeability, $E_{i}$ is the value of exposure of land use/soil permeability pertaining to the $i^{\text {th }}$ FSA. The following procedural steps are followed in GIS for incorporating the information on exposures of soil permeability and land use to flood: 1) the Ontario Surficial Geology dataset for Zone 17 in Ontario is imported into ArcMap; 2) the layer features are symbolized by categorical attributes; 3) to symbolize each soil type with its own colour, the Layer Properties dialogue box is opened, "Symbology" and "Categories" tabs are selected from the left menu, and "unique values" is highlighted; 4) in the Value Field, "SINGLE_PRI" is selected, which represents the single primary material of the soil composition. A colour scheme is selected and then each soil is represented by its own colour in the ArcMap data viewer; 5) the "Select by Location" tool of GIS is used to isolate those soils which fall within a particular FSA; 6) an area calculation is then performed on these "soils of interest" which provides the area of each soil type and the FSA boundaries that the soil area is within. An additional field is entered into the layers attribute table; the name of the field (column) and its type (floating point, integer etc.) are specified. All values are initialized to 0 . The calculator option is then selected to compute the areas of the selected attributes. An advanced Visual Basics Application (VBA) area statement is used to calculate the required areas; 7) the type of each soil can be found in the layers attribute table along with the soils characteristic permeability which varied from "low" to "high"; 8) the results are summarized in a table. A similar procedure is followed for land use, but "category" is symbolized by: Commercial, Government \& Institutional, Open area, Parks and Recreational, Residential, Resource and Industrial, and Water body. The impacts of exposures of land use and soil permeability to flood for FSAs of London are tabulated in Table 4. All

Table 4. Impact of exposures of land use and soil permeability to flood.

\begin{tabular}{ccc}
\hline \multirow{2}{*}{ FSA } & \multicolumn{2}{c}{ Impact of Exposures (standardized value) } \\
\cline { 2 - 3 } & Based on land use & Based on soil permeability \\
\hline N6A & 0.7362 & 0.2139 \\
N6B & 1.0000 & 0.0000 \\
N6C & 0.7562 & 0.9403 \\
N6E & 0.4311 & 0.9497 \\
N6G & 0.3954 & 0.5836 \\
N6H & 0.2481 & 0.5144 \\
N6J & 0.7067 & 0.8668 \\
N6K & 0.3339 & 0.4643 \\
N6L & 0.0000 & 1.0000 \\
N6M & 0.0386 & 0.7239 \\
N6N & 0.0125 & 0.9149 \\
N6P & 0.0122 & 0.7982 \\
N5V & 0.3049 & 0.3906 \\
N5W & 0.7427 & 0.1372 \\
N5X & 0.2357 & 0.3267 \\
N5Y & 0.8250 & 0.2760 \\
N5Z & 0.7938 & 0.4290 \\
\hline
\end{tabular}


the values are standardized with in $[0,1]$ to produce an indicator scores. Table 4 indicates that the exposure of land use for FSA-N6B, which is located in the central part of London, has maximum impact to flood due to presence of more commercial, residential and industrial areas; whereas the exposure of soil permeability has minimum impact to flood, as N6B has high permeable soil with high drainage capacity. The table also indicates that the exposure of land use for FSA-N6L, which is located in the southern part of London, has minimum impact to flood due to presence of more open and recreational areas; whereas the exposure of soil permeability has more impact to flood, as N6L has low permeable soil with less drainage capacity.

\section{Development of the Information System}

Providing a website for people to access flood risk information is an effective way of informing the public about the susceptibility to flooding that they may otherwise not be aware of. The study of Barredo et al. [13] is a contribution to the discussion about the need for communication tools between the natural hazard scientific com- munity and the political \& decision making players in this field. The website can serve as an information center and may provide analysis tools for interactive processing of available flood information. It also provides the opportunity to tailor the presentation of the same information to different types of users according to their needs. According to the program evaluation glossary of USEPA [65], an information system is an organized collection, storage, and presentation system of data and other knowledge for decision making, progress reporting, and for planning and evaluation of programs. It can be either manual or computerized, or a combination of both. The information from the present risk-vulnerability analysis to flood is systematically kept in a computerized information system for more efficient use. The Adobe Dreamweaver Creative Sweet 3 software (http://www.adobe.com/ ap/products/dreamweaver) is used for creating the flood information system. The whole website is based off the Cascading Style Sheets (CSS) template provided in Adobe CS3. The developed information system is easy to navigate. The process starts by providing access to different FSAs of 6 damage centers in the Upper Thames watershed. After selecting the damage center, typing in the first three digits of an FSA will direct the user to information about that FSA. Selected three digits of the FSA activate the search engine that is created using a search engine composer. Information page is available for every FSA region. The information that is displayed for all the users; includes maps, numerical data, and an analysis tool in Microsoft excel spreadsheet format for calculation of flood risk as a function of change in land use. After typing the first three digits of an FSA in an identified cell of the spreadsheet, the user will be directed to the information on flood risk of the FSA, considering the present land use pattern and area under different categories of land use. Area under each land use type can be changed by the user to find out the flood risk under future scenario of land use pattern. It will calculate risk by using (1).

The prototype information system created for this riskvulnerability analysis to flood targets 3 different user categories: 1) general public, 2) decision-makers and 3) water management professionals. The general public has access to a simple explanation of flood risk terminology, tables providing values of vulnerability to flood and a description of what they mean, 100-year and 250-year flood lines, as well as a simple analysis tool for flood risk calculation. Decision-makers are provided with a more detailed description of flood risk terminology and the implications of flooding. They have access to the same flood hazard maps as the general public. Decision-makers are provided with a more detailed and flexible analysis tool which allows the user to change the land use and compare the present level of flood risk with the one obtained under changed land use scenario. This may assist in the analyses of different land development initiatives and their consequences on flood risk. Water management professionals are presented with the most detailed descriptions and the most technical flood related information. They are provided a very detailed numerical breakdown of vulnerability and exposures of land use and soil permeability, including a list of all indicators used in the analyses. They also have access to the flood hazard maps similar to those provided to the general public and the decision-makers. The analysis tool available to professionals is the same as one provided to the decision-makers. The professionals are the only user with access to a "raw data" containing all of the numerical data used for the flood risk analyses. Screenshots of the opening page of prototype information system and analysis tool are shown in Figures 6(a) and (b). The information system is user-friendly and the details can be found in Black et al. [66].

\section{Conclusions}

The present study analyzes flood risk and vulnerability to flood in the Upper Thames River basin, Ontario, Canada. It deals with a large region as a case study with six major damage centers in the watershed for flood risk mapping considering probability of occurrence, four components of vulnerability and exposures of land use and soil permeability to flood. The impact of inundation of critical facilities and road bridges on infrastructure vulnerability is analyzed. New indices are introduced in the infrastructure vulnerability to flood, for example - length of railway, length of road, number of major intersections, 


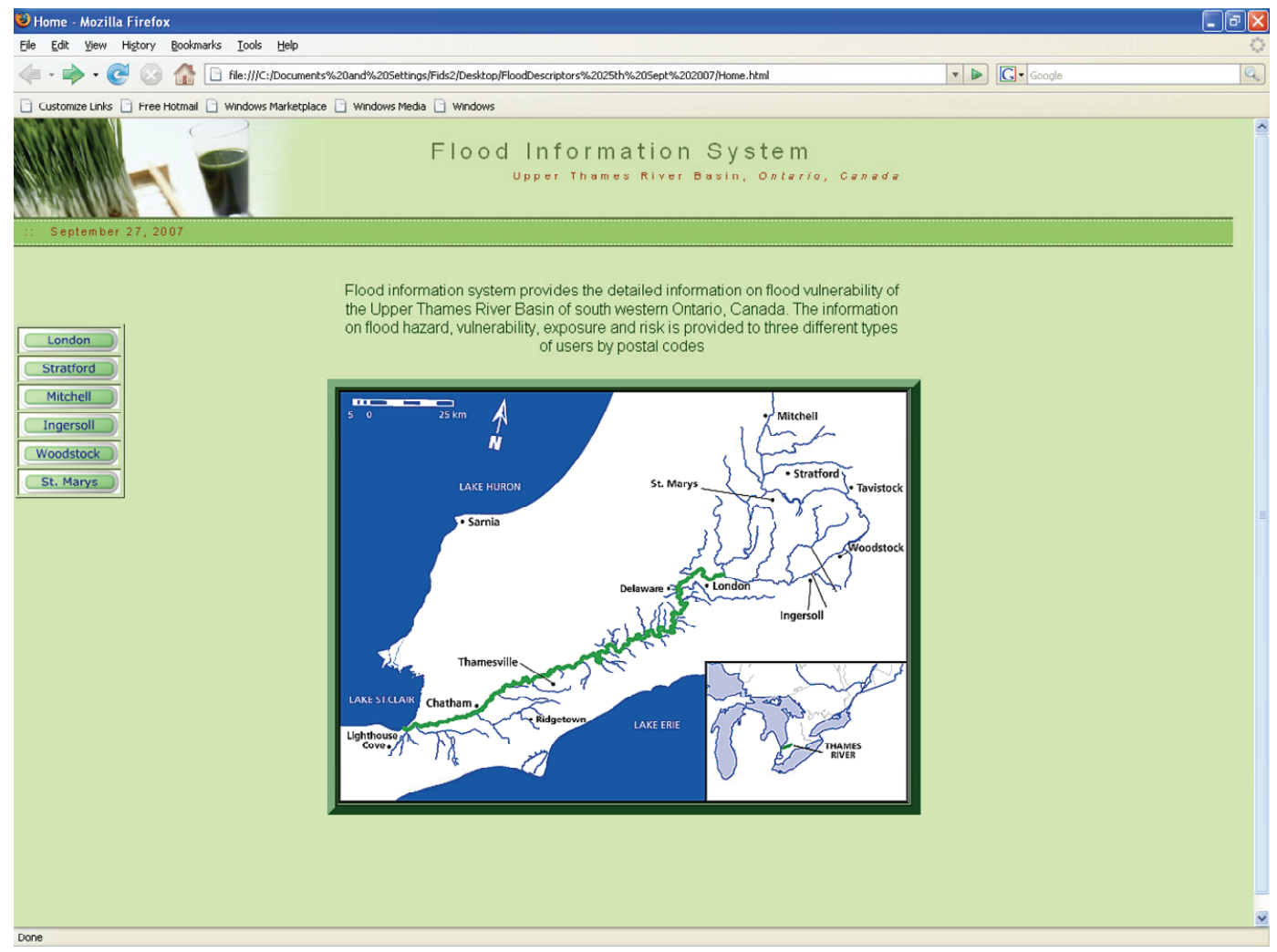

(a)

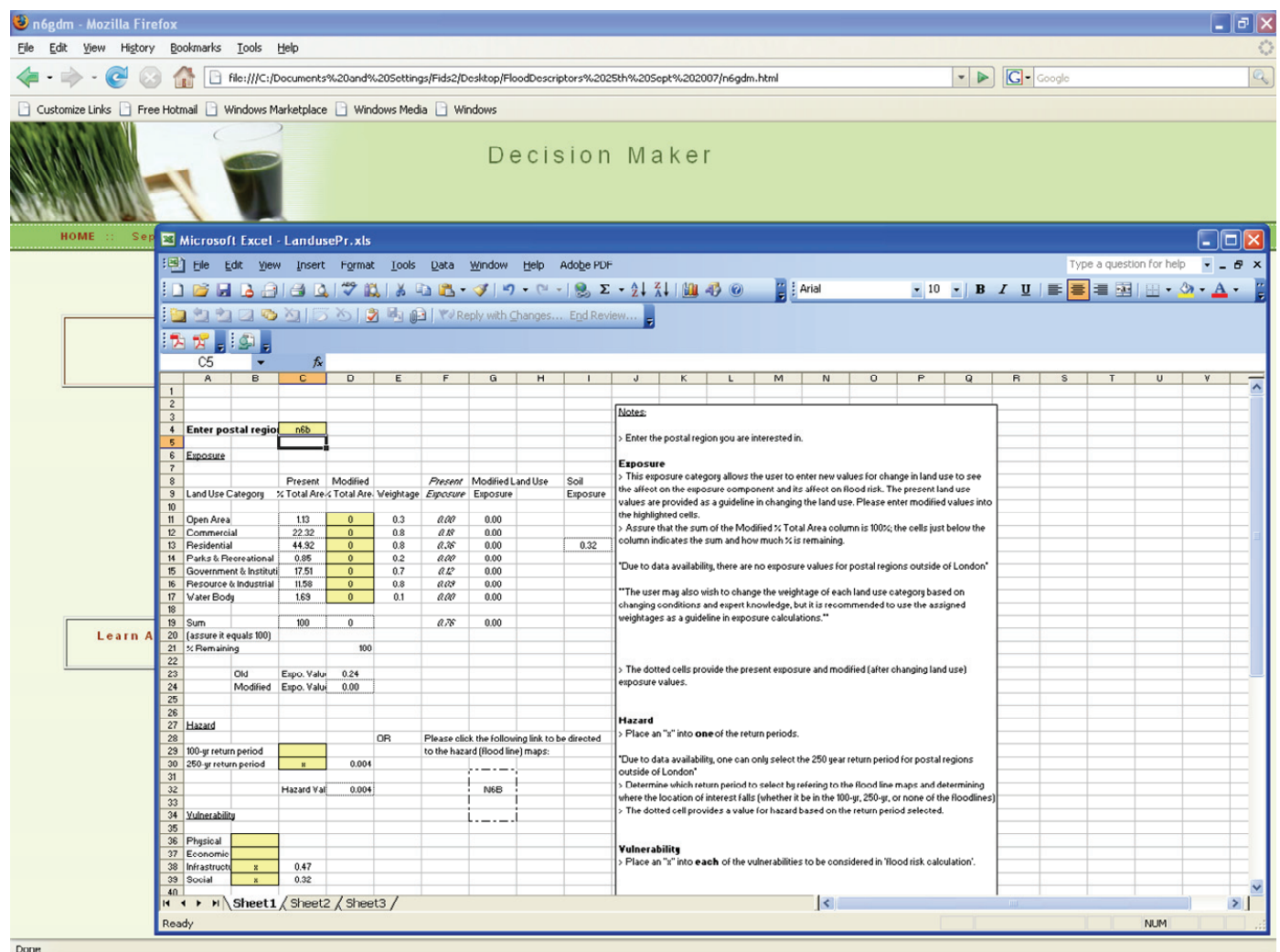

(b)

Figure 6. (a) Opening page of the information system; (b) analysis tool for decision makers. 
number of critical facilities and road bridges. Typically, exposures of land use and soil permeability have been included as a component of risk. The minimum and maximum values of vulnerability are considered in the standardization process instead of using the conventional formula for standardization. A user-friendly information system is designed to systematically represent all flood information. The study provides an "analysis tool" for estimation of flood risk as a consequence of change in land use.

The present study has some limitations and offers some benefits for future development. In the flood information system all the indices of infrastructure vulnerability for critical facilities are not considered due to unavailability of data. For example, emergency shelters, nursing homes, public buildings, police stations, water treatment or sewage processing plants, utilities, railroad stations, airports and government facilities; which are identified critical facilities [27,62]. The assignment of Degree of Importance (DI) for calculation of impact inundation of important service buildings, emergency service stations and road bridges across the river on infrastructure vulnerability, and in calculation for exposures of land use and soil permeability is dependent on the perspective of decision-makers or floodplain planners, which introduces some uncertainty due to vagueness or imprecision in the model. This uncertainty due to imprecision in the assignment of DI may be addressed in the flood risk calculation. In the present system only two flood lines are available, e.g., 100- and 250-years flood lines, which limit the calculation of flood risk. The impact of critical facilities and road bridges across the river on infrastructure vulnerability is calculated only for the City of London as per the availability of data. The same analysis may be performed for other damage centers in the watershed. In future studies, different shapes and sizes of "vulnerability shapes" with finer grid system and actual population density can be considered for determining the impact of inundation of critical facilities and road bridges. The impact of climate change is not considered in the current version of the system. The hazard maps or the position of flood lines will change if the climate change impacts are taken into consideration [67]. The values of flood risk for different postal codes may be easily updated to include the impact of climate change. No hydrologic calculation is performed in the present study to find out current position of flood lines. A sophisticated hydrologic modeling may be implemented for finding out the current positions of flood lines and result in more accurate calculation of flood risk. The proposed methodologies of flood risk mapping are not limited to the present case study and may be easily applied to other watersheds.

\section{Acknowledgements}

The authors sincerely thank the Upper Thames River Co- nservation Authority, Statistics Canada, Canadian Homebuyers Guide, Serge A. Sawyer map library \& the IDLS library at The University of Western Ontario for providing data used in this study. Work presented in this paper has been conducted under the research grant by the Natural Sciences and Engineering Research Council of Canada.

\section{References}

[1] P. J. Floyd, "Reducing Flood Risks," Floods and Flood Management, 1992, pp. 419-435.

[2] E. J. Plate, "Flood Risk and Flood Management," Journal of Hydrology, Vol. 267, No. 1-2, 2002, pp. 2-11.

[3] A. Becker and U. Grünewald, "Disaster Management: Flood Risk in Central Europe," Science, Vol. 300, No. 5622, 2003, p. 1099.

[4] D. P. Loucks, J. R. Stedinger, D. W. Davis and E. Z. Stakhiv, "Private and Public Responses to Flood Risks," International Journal of Water Resources Development, Vol. 24, No. 4, 2008, pp. 541-553.

[5] M. J. Purvis, P. D. Bates and C. M. Hayes, “A Probabilistic Methodology to Estimate Future Coastal Flood Risk Due to Sea Level Rise," Coastal Engineering, Vol. 55, No. 12, 2008, pp. 1062-1073.

[6] R. J. Dawson, L. Speight, J. W. Hall, S. Djordjevic, D. Savic and J. Leandro, "Attribution of Flood Risk in Urban Areas," Journal of Hydroinformatics, Vol. 10, No. 4, 2008, pp. 275-288.

[7] H. Apel, G. T. Aronica, H. Kreibich and A. H. Thieken, "Flood Risk Analyses-How Detailed do We Need to be?" Natural Hazards, Vol. 49, No. 1, 2009, pp. 79-98.

[8] P. Garrett, “Assessing Flood Risk," Water Bull, Vol. 355, 1989, p. 9.

[9] B. Burrell and J. Keefe, "Flood Risk Mapping in New Brunswick: A Decade Review," Canadian Water Resources Journal, Vol. 14, No. 1, 1989, pp. 66-77.

[10] D. G. Morris and R. W. Flavin, "Flood Risk Map for England and Wales," Report - UK Institute of Hydrology, 1996, p. 130.

[11] D. D. Shrubsole, "Flood Management in Canada at the Crossroads," Global Environmental Change Part B: Environmental Hazards, Vol. 2, No. 2, 2000, pp. 63-75.

[12] J. W. Hall, R. J. Dawson, P. B. Sayers, C. Rosu, J. B. Chatterton and R. Deakin, "A Methodology for Nationalscale Flood Risk Assessment," Proceedings of the Institution of Civil Engineers: Water and Maritime Engineering, Vol. 156, No. 3, 2003, pp. 235-247.

[13] J. I. Barredo, A. de Roo and C. Lavalle, "Flood Risk Mapping at European Scale," Water Science and Technology, Vol. 56, No. 4, 2007, pp. 11-17.

[14] S. L. Cutter, (Ed.) "American Hazardscapes: The Regionalization of Hazards and Disasters," Joseph Henry Press, Washington, D.C., 2001, p. 211.

[15] S. L. Cutter, "Vulnerability to Environmental Hazards," Progress in Human Geography, Vol. 20, No. 4, 1996, pp. 529-539. 
[16] S. Bender, "Development and Use of Natural Hazard Vulnerability-Assessment Techniques in the Americas," Natural Hazards Review, American Society of Civil Engineers, 2002, pp. 136-138.

[17] L. Roy, R. Leconte, F. Brissette and C. Marche, "The Impact of Climate Change on Seasonal Floods of a Southern Quebec River Basin," Hydrological Processes, Vol. 15, No. 3, 2001, pp. 3167-3179.

[18] N. Nirupama and S. Simonovic, "Increase in Flood Risk Due to Urbanization: A Canadian Example," Natural Hazards, Vol. 40, No. 1, 2007, pp. 25-41.

[19] M. Morris-Oswald and S. Simonovic, "Assessment of the Social Impacts of Flooding for Use in Flood Management in the Red River Basin," Report Submitted to the International Red River Basin Task Force, International Joint Commission, Winnipeg, Manitoba, 1997. http://www.ijc. org/php/publications/html/assess.html

[20] E. Enarson, "Women, Work, and Family in the 1997 Red River Valley Flood: Ten Lessons Learned," Disaster Preparedness Resources Centre, University of British Columbia, British Columbia, Canada, 1999.

[21] E. Enarson and J. Scanlon, "Gender Patterns in Flood Evacuation: A Case Study in Canada's Red River Valley," Applied Behavioural Science Review, Vol. 7, No. 2, 1999, pp. 103-124.

[22] Natural Hazard Center, "Evaluation of a Literature Review of the Social Impacts of the 1997 Red River Flood," Report Submitted to the International Red River Basin Task Force, International Joint Commission. University of Colorado, Boulder, Colorado, USA, 1999, p. 11.

[23] P. Blaikie, R. Cannon, I. Davis and B. Wisner, "At Risk: Natural Hazards, People's Vulnerability, and Disasters," Routledge, New York, 1994, p. 284.

[24] P. M. Kelly and W. N. Adger, "Theory and Practice in Assessing Vulnerability to Climate Change and Facilitating Adaptation," Climatic Change, Vol. 47, No. 4, 2000, pp. 325-352.

[25] B. Montz and T. Evans, "GIS and Social Vulnerability Analysis," In: E. Gruntfest and J. Handmer, Eds., Coping with Flash Floods, Kluwer Academic Publishers, Netherlands, 2001, pp. 37-48.

[26] S. L. Cutter, J .T. Mitchell and M. S. Scott, "Revealing the Vulnerability of People and Places: A Case Study of Georgetown County, South Carolina," Annals of the Association of American Geographers, Vol. 90, No. 4, 2000, pp. 713-737.

[27] L. K. Flax, R. W. Jackson and D. N. Stein, "Community Vulnerability Assessment Tool Methodology," Natural Hazards Review, American Society of Civil Engineers, Vol. 3, No. 4, 2002, pp. 163-176.

[28] S. L. Cutter, B. J. Boruff and W. L. Shirley, "Social Vulnerability to Environmental Hazards," Social Science Quarterly, Vol. 84, No. 2, 2003, pp. 242-261.

[29] R. Blong, “A New Damage Index," Natural Hazards, Vol. 30, No. 1, 2003, pp. 1-23.

[30] N. T. Carter, "Flood Risk Management: Federal Role in Infrastructure," CRS Report for Congress, 2005, http:// fpc. state.gov/documents/organization/56095.pdf

[31] J. Chakraborty, G. A. Tobin and B. E. Montz, "Population Evacuation: Assessing Spatial Variability in Geophysical Risk and Social Vulnerability to Natural Hazards," Natural Hazards Review, American Society of Civil Engineers, Vol. 6, No. 1, 2005, pp. 23-33.

[32] L. Rygel, D. O'Sullivan and B. Yarnal, "A Method for Constructing a Social Vulnerability Index: An Application to Hurricane Storm Surges in a Developed Country," Mitigation and Adaptation Strategies for Global Change, Vol. 11, No. 3, 2006, pp. 741-764.

[33] A. Werritty, D. Housto, T. Ball, A. Tavendale and A. Black, "Exploring the Social Impacts of Flood Risk and Flooding in Scotland," Scottish Executive Social Research, Edinburgh, 2007.

[34] S. K. Sinnakaudan, A. Ab Ghani, M. S. S. Ahmad, and N. A. Zakaria, "Flood Risk Mapping For Pari River Incorporating Sediment Transport," Environmental Modelling and Software, Vol. 18, No. 2, 2003, pp. 119-130.

[35] J. Bai, C. Wang, Z. Niu, S. Qi and G. Li, "Utilizing Remote Sensed TM Images and Meteorological Data to Plan Flood Risk Area," Proceedings of The International Society for Optical Engineering, Vol. 5232, 2006, pp. 370377.

[36] F. Forte, L. Pennetta and R. O. Strobl, "Historic Records and GIS Applications for Flood Risk Analysis in the Salento Peninsula (Southern Italy)," Natural Hazards and Earth System Science, Vol. 5, No. 6, 2005, pp. 833-844.

[37] R. Abdalla, C. V. Tao, H. Wu and I. A. Maqsood, "GISSupported 3D Approach for Flood Risk Assessment of the Qu'Appelle River, Southern Saskatchewan," International Journal of Risk Assessment and Management, Vol. 6, No. 4-6, 2006, pp. 440-455.

[38] D. G. Hadjimitsis, "The Use of Satellite Remote Sensing and GIS for Assisting Flood Risk Assessment-A case study of Agriokalamin Catchment Area in Paphos-Cyprus," Proceedings of The International Society for Optical Engineering, Vol. 6742, No. 67420Z, 2007.

[39] K. Smith, "Environmental Hazards: Assessing Risk and Reducing Hazards," 3rd Edition, Routledge (Taylor \& Francis Group), New York, 2001, p. 392.

[40] J. Lowry, H. Miller and G. Hepner, "A GIS-Based Sensitivity Analysis of Community Vulnerability to Hazardous Contaminants on the Mexico/U.S. Border," Photogrammetric Engineering \& Remote Sensing, Vol. 61, No. 11, 2005, pp. 1347-1359.

[41] L. A. Varga, D. Radulescu and R. Drobot, "Romanian National Strategy for Flood Risk Management," IAHSAISH Publication, Vol. 323, 2008, pp. 75-86.

[42] H. Chang, J. Franczyk and C. Kim, "What is Responsible for Increasing Flood Risks? The Case of Gangwon Province, Korea," Natural Hazards, Vol. 48, No. 3, 2009, pp. 339-354.

[43] P. Tran, F. Marincioni, R. Shaw, M. Sarti and A. L. Van, "A Flood Risk Management in Central Viet Nam: Challenges and Potentials," Natural Hazards, Vol. 46, No. 1, 2008, pp. 119-138. 
[44] S. Forster, B. Kuhlmann, K. E. Lindenschmidt and A. Bronstert, "Assessing Flood Risk for a Rural Detention Area," Natural Hazards and Earth System Science, Vol. 8, No. 2, 2008, pp. 311-322.

[45] M. Dilley, R. S. Chen, U. Deichmann, A. L. Lerner-Lam, M. Arnold, J. Agwe, P. Buys, O. Kjekstad, B. Lyon and G. Yetman, "Natural Disasters Hotspots: A Global Risk Analysis," Synthesis Report, The World Bank, Washington, D.C., 2005.

[46] M. Arnold, R. Chen, U. Deichmann, M. Dilley, A. Lerner-Lam, R. Pullen and Z. Trohanis, "Natural Disaster Hotspots: Case Studies," Disaster Risk Management Series, No. 6, The World Bank, Washington, D.C., 2006.

[47] UN, "Internationally Agreed Glossary of Basic Terms Related to Disaster Management," United Nations Department of Humanitarian Affairs, Geneva, 1992.

[48] B. Merz and A. H. Thieken, "Flood Risk Analysis: Concepts and Challenges," O"sterreichische Wasser und Abfallwirtschaft, Vol. 56, No. 3-4, 2004, pp. 27-34.

[49] EU, "European Flood Directive: Richtlinie 2007/60/EG des Europäischen Parlaments und des Rates vom 23. Oktober 2007 über die Bewertung und das Management von Hochwasserrisiken," Amtsblatt der Europäischen Union, L288, pp. 27-34.

[50] W. Kron, "Flood Risk = Hazard $\bullet$ Values $\bullet$ Vulnerability," Water International, Vol. 30, No. 1, 2005, pp. 58-68.

[51] S. Y. Wu, B. Yarnal and A. Fisher, "Vulnerability of Coastal Communities to Sea-Level Rise: A Case Study of Cape May County, New Jersey, USA," Climate Research, Vol. 22, No. 4, 2002, pp. 255-270.

[52] Y. Huang, Y. Zou, G. Huang, I. Maqsood and A. Chakma, "Flood Vulnerability to Climate Change through Hydrological Modeling: A Case Study of the Swift Current Creek Watershed in Western Canada," Water International, Vol. 30, No. 1, 2005, pp. 31-39.

[53] A. Hebb and L. Mortsch, "Floods: Mapping Vulnerability in the Upper Thames Watershed under a Changing Climate," Project Report XI, University of Waterloo, 2007, pp. 1-53.

[54] R. Grosshans, H. Venema and S. Barg, "Geographical Analysis of Cumulative Threats to Prairie Water Resources: Mapping Water Availability, Water Quality, and Water Use Stresses," International Institute for Sustainable Development, Winnipeg, Manitoba, 2005, p. 40.

[55] M. Helsten and D. Davidge, "Flood Damage Estimation in the Upper Thames River Watershed CFCAS Project: Assessment of Water Resources Risk and Vulnerability to Changing Climatic Conditions," Project Report VII, Up- per Thames River Conservation Authority, 2005, pp. $1-46$.

[56] H. Apel, A. H. Thieken, B. Merz and G. A. Blöschl, "Probabilistic Modelling System for Assessing Flood Risks," Natural Hazards, Vol. 38, No. 1-2, 2006, pp. 79-100.

[57] W. Feller, "An Introduction to Probability Theory and its Applications," 3rd Edition, John Wiley and Sons, New York, Vol. I, 1968.

[58] Environmental Systems Research Institute (ESRI), "Arc 9.2. ESRI,“ Redlands, California, 2006.

[59] S. E. Mustow, R. F. Burgess and N. Walker, "Practical Methodology for Determining the Significance of Impacts on the Water Environment," Water and Environment Journal, Vol. 19, No. 2, 2005, pp. 100-108.

[60] P. A. Keddy and A. A. Reznicek, "Great Lakes Vegetation Dynamics: The Role of Fluctuating Water Levels and Buried Seeds," Journal of Great Lakes Research, Vol. 12, No. 1, 1986, pp. 25-36.

[61] S. Efromovich, "Nonparametric Curve Estimation: Methods, Theory and Applications," Springer-Verlag, New York, 1999.

[62] D. Odeh, "Natural Hazards Vulnerability Assessment for Statewide Mitigation Planning in Rhode Island," Natural Hazards Review, ASCE, Vol. 3, No. 4, 2002, pp. 177187.

[63] A. Peck, S. Karmakar and S. P. Simonovic, "Physical, Economical, Infrastructural and Social Flood RiskVulnerability Analyses in GIS," Water Resources Research Report No. 057, Facility for Intelligent Decision Support, Department of Civil and Environmental Engineering, London, Ontario, Canada, 2007.

[64] A. Sullivan, J. L. Ternan and A. G. Williams, "Land Use Change and Hydrological Response in the Camel Catchment, Cornwall," Applied Geography, Vol. 24, No. 2, 2004, pp. 119-137.

[65] U. S. Environmental Protection Agency (USEPA), "Program Evaluation Glossary". http://www.epa.gov/evaluate/ glossary/i-esd.htm

[66] J. Black, S. Karmakar and S. P. Simonovic, "A WebBased Flood Information System," Water Resources Research Report No. 056, Facility for Intelligent Decision Support, Department of Civil and Environmental Engineering, London, Ontario, Canada, 2007.

[67] P. Prodanovic and S. P. Simonovic, "Inverse Flood Risk Modelling of the Upper Thames River Basin," Water Resources Research Report No. 052, University of Western Ontario, London, Ontario, Canada, 2006. 